\title{
Mikrobiyal Yakıt Hücresinde Grafen Kaplı Nikel-Titanyum (NiTi) Alaşımının Anot Elektrotu Olarak Kullanılması
}

\author{
Ergin Taşkan ${ }^{1 *}$, Selman Bulak ${ }^{1}$, Banu Taşkan $^{1}$, Merivan Şaşmaz $^{2}$, Engin Gürtekin $^{1}$, Ali Bayri $^{3}$ \\ ${ }^{1}$ Çevre Mühendisliği Bölümü, Mühendislik Fakültesi, Fırat Üniversitesi, Elazı̆̆g, Türkiye \\ ${ }^{2}$ Fizik, Fen-Edebiyat Fakültesi, Adıyaman Üniversitesi, Adıyaman, Türkiye \\ ${ }^{3}$ Fizik, Fen-Edebiyat Fakültesi, İnönü Üniversitesi, Malatya, Türkiye \\ *1 etaskan@firat.edu.tr ${ }^{1}$ selmanbulak@gmail.com, btaskan@ firat.edu.tr, egurtekin@ @irat.edu.tr ${ }^{2}$ \\ merivansasmaz@gmail.com³ ali.bayri@inonu.edu.tr
}

\begin{abstract}
Öz: Bu çalışmada, grafen kaplı nikel-titanyum (NiTi) alaşımı üretilerek mikrobiyal yakıt hücresinde (MYH) anot elektrotu olarak kullanılmıştır. Çalışmada çift bölmeli bir MYH reaktörü sürekli modda işletilmiş ve elektrik üretim performansı detaylı bir şekilde araştırılmıştır. MYH reaktörünün ürettiği maksimum güç yoğunluğu $2043 \mathrm{~mW} / \mathrm{m}^{2}$ olarak elde edilmiştir. Sistemin toplam iç direnci $437.7 \Omega$ olarak ölçülmüştür. İşletme süresi sonunda anot elektrotu yüzeyinden alınan SEM görüntülerinde biyofilm yapısında genellikle yuvarlak şekilli mikroorganizmaların mevcut olduğu tespit edilmiştir. Biyofilm numunesine uygulanan PCR-DGGE analizleri elektrot yüzeyinde Shewanella oneidensis ve Pseudomonas aeruginosa gibi elektrik üretiminde etkin mikrobiyal türlerin mevcut olduğunu göstermiştir.
\end{abstract}

Anahtar kelimeler: Mikrobiyal yakıt hücresi (MYH), Anot elektrotu, Nikel-titanyum (NiTi) alaşımı, Grafen kaplama, Güç yoğunluğu

\section{The Usage of Graphene Coated Nickel-titanium (NiTi) Alloy in Microbial Fuel Cell as Anode Electrode}

Abstract: In this study, graphene coated nickel-titanium (NiTi) alloy was produced and used as an anode material in microbial fuel cell (MFC). A double chamber MFC operated in a continuous mode, and electricity generation performance was investigated in detail. The max power density of MFC was $2043 \mathrm{~mW} / \mathrm{m}^{2}$. The total internal resistance of MFC was measured to be $437.7 \Omega$. The SEM images showed that a round shaped bacteria present in the biofilm structure. PCR-DGGE analysis demonstrated that Shewanella oneidensis and Pseudomonas aeruginosa, which are called electrogen bacteria, were present in the biofilm.

Key words: Microbal fuel cell (MFC), Anode electrode, Nickel-titanium (NiTi) alloy, Graphene coating, Power density.

\section{Giriş}

MYH'ler organik atıklardan elektrik enerjisinin üretilebildiği biyoreaktörlerdir. Klasik bir MYH reaktörü anot ve katot bölmesinden oluşmakta ve bu iki bölmeyi birbirinden fiziksel olarak ayıran proton değişim membranı (PDM) bulunmaktadır [1] . Bir MYH reaktöründe üretilen elektrik miktarını etkileyen en önemli faktörlerden biri sistemde kullanılan anot malzemesidir. İyi bir anot malzemesi yüksek elektriksel iletkenliğe, mikroorganizmalar ile biyolojik uyumluluğa ve yüksek spesifik yüzey alanına sahip olmalıdır [2]. Şu ana kadar yapılan MYH çalışmalarında genellikle karbon tabanlı malzemeler anot elektrotu olarak kullanılmıştır [3]. Fakat bu malzemeler düşük elektriksel iletkenliğe sahip olduğundan dolayı birçok yeni malzeme MYH'lerde anot elektrotu olarak kullanılmaya başlanmıştır.

NiTi alaşımları biyouyumluluğundan dolayı sağlık sektöründe ve daha birçok alanda oldukça geniş bir kullanım alanına sahiptir [4]. Damar tıkanıklığını açıcı stenler, ortodontide diş telleri, ortopedik implantlar, gözlük çerçeveleri vb. tedavilerde kullanılmaktadır [5]. Bu malzemelerin canlı dokular ve mikroorganizmalar ile biyouyumluluğu oldukça yüksektir. Bu nedenle MYH'lerde anot elektrotu olarak kullanım için ciddi bir potansiyele sahiptir. Ancak bu malzemelerin yüzeyinin düz yapıda olması mikoorganizmaların tutunmasını güçleştirmekte ve biyofilm oluşumunu kısıtlamaktadır. Bu nedenle, NiTi malzemelerin MYH'de kullanım potansiyelini arttırmak için yüzey modifikasyonu gerekmektedir. Literatürde anot malzemeleri için kullanılan en iyi yüzey modifikasyonu grafen kullanılarak yapılmaktadır. Grafenin yüksek elektriksel iletkenliği, mekanik

\footnotetext{
* Sorumlu yazar: etaskan@ firat.edu.tr. Yazarların ORCID Numarası: ${ }^{1 *} 0000-0002-9620-8644,{ }^{1} 0000-0001-7751-1165,{ }^{2} 0000-0002-4243-$ 7169, ${ }^{1} 0000-0003-3075-7891,{ }^{3} 0000-0002-8197-1604$.
} 
dayanımı, mikroorganizmalar ile biyolojik uyumu ve uygun yüzey yapısına sahip olmasından dolayı grafen, MYH çalışmalarında elektrot modifikasyonu için kullanılmıştır. Hou ve diğ., (2015) paslanmaz çelik elyaf keçeyi grafen ile modifiye etmiş ve MYH'de anot elektrotu olarak kullanmışlardır; çalışma sonucunda yapılan modifikasyonun modifiye edilmemiş anotlardaki elektrokimyasal kinetikleri iyileştirilerek MYH'nin iç direncini önemli derecede azaltıldığı rapor edilmiştir. Bir diğer çalışmada Hsu ve diğ., (2017) paslanmaz çelik elektrotu grafen ile modifiye ederek güç üretiminde 1.5-4.5 kat artış sağlamış ve MYH iç direncini düşürdüğünü rapor etmişlerdir. Xiao ve diğ., (2012) tarafından yapılmış bir çalışmada gevrek grafen ve rulo kâğıt tarzı grafen MYH'lerde karbon kumaş elektrotu modifiye etmek için kullanılmış ve maksimum güç yoğunluğu sırasıyla 2.5 ve $3.3 \mathrm{~W} / \mathrm{m}^{3}$ olarak elde edilmiştir. Buna karşın, modifiye edilmiş elektrotun kullanılmadığı durumda üretilen güç miktarının $0.3 \mathrm{~W} / \mathrm{m}^{3}$ olduğu rapor edilmiştir. Zhang ve diğ., (2011) grafen ile modifiye edilmiş düz paslanmaz çelik tel anotların, grafen ile modifiye edilmemiş anotlar ile kıyaslandığında maksimum güç yoğunluğunun 18 kat daha fazla iyileștirebileceğini belirtmiștir. Anot elektrotu yüzeyinde elektrokimyasal olarak aktif biyofilmin oluşumu ile organik maddelerden üretilen elektronların anot yüzeyine daha verimli bir şekilde aktarılması sağlanmaktadır. Literatür verileri, grafen kullanılarak yapılan modifikasyon işleminin anot yüzeyinin iyileştirilmesi için kullanılabileceğini göstermiştir.

Bu çalıșmada, yeni üretilen NiTi alaşımı grafen ile kaplanarak MYH'de anot elektrotu olarak kullanılmıștır. Grafen ile kaplanan NiTi alaşımının elektrik üretim performansı polarizasyon analizi ve nyquist analizleri ile belirlenmiştir. İşletme süresi sonunda elektrot yüzeyinde oluşan biyofilm yapısı SEM analizi ile görüntülenmiştir. Ayrıca biyofilm yapısındaki mikrobiyal komunite PCR-DGGE analizi ile detaylı bir şekilde araştırılmıştır.

\section{Materyal ve Metot}

\subsection{NiTi alaşımının üretimi ve modifikasyonu}

NiTi alaşımı, Ni/Ti atomikçe oranı \%50.5 ve \%49.5 olacak şekilde, çapları 3-25 mm arası değişen ve \% 99.95 saflıktaki nikel topları ve \% 99.99 saflıktaki granül şeklindeki titanyum parçalarının ark eritme cihazı ile argon gazı altında üretilmiştir. Üretimi yapılan NiTi alaşımının grafen ile kaplanması işleminde toz grafit ( 325 mesh) kullanılarak grafen oksit $(\mathrm{GO})$ sentezlenmiştir. $120 \mathrm{ml}$ sülfürik asit $\left(\mathrm{H}_{2} \mathrm{SO}_{4}\right)$ ile karıştırılan $3 \mathrm{~g}$ toz halindeki grafit iyice ıslanması için $30 \mathrm{dk}$ boyunca $5{ }^{\circ} \mathrm{C}$ sıcaklıkta ve $600 \mathrm{rpm}$ 'de karıştırılmıştır. Ardından karışım hızlı bir şekilde karıştırılırken sıcaklık $10^{\circ} \mathrm{C}$ 'yi geçmeyecek şekilde yavaş yavaş potasyum permanganat $\left(\mathrm{KMnO}_{4}\right)$ eklenmiştir. Elde edilen karışım $35^{\circ} \mathrm{C}^{\prime}$ de 3,5 sa karıştırıldıktan sonra sıcaklığı $100{ }^{\circ} \mathrm{C}$ 'yi geçmeyecek şekilde saf su ilave edilmiştir. Son olarak da $25 \mathrm{ml} \% 30$ saflıktaki hidrojen peroksit $\left(\mathrm{H}_{2} \mathrm{O}_{2}\right)$ yavaş yavaş eklenmiştir. $6 \mathrm{dk}$ ve 8500 rpm'e ayarlanmış santrifüj yardımıyla çöktürülen numenin $2 \mathrm{kez}$ saf su ve $2 \mathrm{kez} \% 20$ 'lik $\mathrm{HCl}$ çözeltisiyle yıkanmasından sonra $1 \mathrm{kez}$ daha su ile yıkanarak işlem tamamlanmıştır.

\subsection{MYH reaktörünün kurulumu ve ișletimi}

Çalışmada çift bölmeli (H tipi) bir MYH reaktörü kullanılmıştır (Şekil 1). Reaktörünün her bir bölmesinin efektif çalışma hacmi 300 ml'dir. MYH'nin anot ve katot bölmesi PDM membranı (Ultrex CMI 7000) ile fiziksel olarak birbirinden ayrılmıştır.

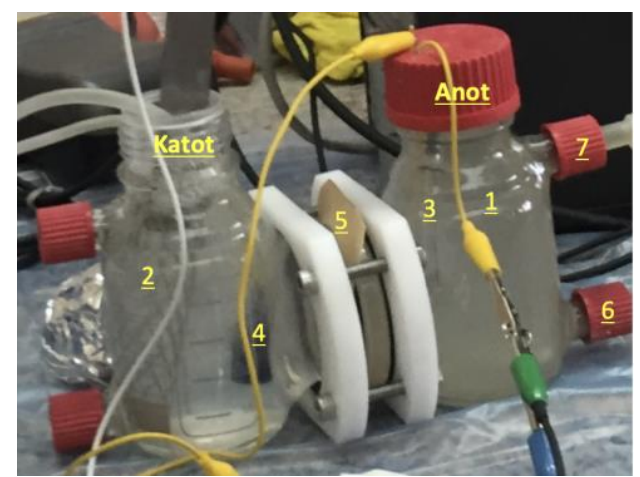

Şekil 1. Çalı̧̧mada kullanılan MYH reaktörü. 1: Anot elektrotu, 2: Katot elektrotu, 3: Referans elektrot (Ag$\mathrm{AgCI}$ ), 4: Hava taşı, 5: Proton değişim membranı (Ultrex CMI 7000), 6: Besleme, 7: Çıkış 
PDM membranı kullanılmadan önce \%4'lük NaCI çözeltisinde 24 saat bekletilmiştir. Anot ve katot elektrotları $10 \Omega$ direnç kullanılarak sabitlenmiştir. Anot bölmesini aşılamak amacıyla anaerobik çürütücü ve sediment ortamından alınan aşı çamurları eşit olarak karıştırılmış ve anot hacminin 1/10 oranında olacak şekilde ilave edilmiştir. Daha sonra anot bölmesi sentetik olarak hazırlanmış atıksu ile doldurulmuş ve 10 dk süreyle azot gazı verilerek anaerobik şartlar oluşturulmuştur. Katot bölmesi $50 \mathrm{mM}$ fosfat tamponu ile doldurulmuş ve hava taşı kullanılarak akvaryum pompası ile sürekli olarak havalandırılmıştır. Anot bölmesine hidrolik bekletme süresi (HBS) 2 gün olacak şekilde reaktör beslemesi yapılmıştır. Sentetik atıksu bileşimi Zheng ve diğ., (2015) belirtildiği şekilde hazırlanmıştır. Substrat kaynağı olarak asetat (400 mg/L KOİ) kullanılmıştır.

\subsection{Analizler \\ 2.3.1. Elektrokimyasal analizler}

MYH reaktöründe üretilen voltajı ölçmek amacıyla çok kanallı Agilent 34410A Data Acqusition/Switch Unit multimetre kullanılmıştır. MYH reaktörlerinde üretilen voltaj değerleri, Agilent Benchlink Data Logger 3 V4.3 yazılımı kullanılarak $1 \mathrm{dk}$ aralıklarla on-line olarak bilgisayara aktarılarak kaydedilmiştir. Elektrokimyasal empedans analizi, Gamry Interface 1000 potansiyostat kullanılarak $5 \mathrm{mV}$ genlikli sinyal ile $0,1 \mathrm{~Hz}$ ile $100 \mathrm{kHz}$ frekans aralığında gerçekleştirilmiştir. MYH reaktörlerinin farklı bileşenlerine ait direnç değerleri Gamry Echem Analyst V6.25 yazılımı ile model oluşturularak belirlenmiştir. Lineer sweep voltametri analizi (LCV), $0,25 \mathrm{mV} / \mathrm{s}$ tarama hızında $\mathrm{Ag} / \mathrm{AgCl}$ referans elektrotu kullanılarak gerçekleştirilmiştir. MYH'de üretilen voltaj (V) ve güç (P) denklem 1 ve denklem 2 kullanılarak hesaplanmıştır.

$V=I . R$

$P=I . V=I^{2} . R$

Formülde;

V: Potansiyel, volt (V), I: Akım, amper (A), R: Direnç, ohm, P: Güç, watt. ifade etmektedir.

\subsubsection{Mikrobiyal analizler}

MYH reaktörünün işletme süresi sonunda anot elektrotu yüzeyinden biyofilm numunesi alınarak mikroorganizmalara ait genomik DNA, UltraClean Soil DNA izolasyon kiti kullanılarak gerçekleştirilmiştir. Bakterilere ait 16S rRNA genlerinin çoğaltılması için TECHNE/TC-512 marka PCR cihazı kullanılmıştır. PCR işleminden sonra analizin başarısını kontrol etmek amacıyla PCR ürünleri \%1'lik (w/v) agaroz jel içerisinde 100 V'da 20 dk süre ile yürütülmüştür. PCR işleminde kullanılan forward ve reverse primerlerin baz dizilimleri Tablo 1 'de verilmiştir. Çoğaltılan hedef genler denatüre gradyan jel elektroforez (DGGE) işlemine tabi tutulmuştur. DGGE işlemi, INGENY phor L-2 cihazı kullanılarak gerçekleştirilmiştir. Analiz için hazırlanan jel, \%35-60 arasında değişen bir gradyanta (\%100'lük denatürant, 7 M üre, \%40 Akrilamid bis (v/v) ve formamit) sahip olup, 1XTAE tampon çözeltisi içerisinde \%8 poliakrilamid jel içermektedir. DGGE analizinin ardından saf türlere ait dizi analizi gerçekleştirilmiş ve baskın olan türler belirlenmiştir.

\section{Bulgular ve Tartışma}

\subsection{Elektrot performansı}

Çalışmada MYH reaktöründe üretilen güç miktarlarını tespit etmek amacıyla LCV analizi yapılmış ve elde edilen veriler kullanılarak polarizasyon ve güç eğrileri oluşturulmuştur. Çalışmada kullanılan MYH reaktörüne ait V-A ve P-A eğrileri, Şekil 2A ve Şekil 2B'de görülmektedir. Sistemde 4.16 A/m²'lik akım yoğunluğunda 2043 $\mathrm{mW} / \mathrm{m}^{2}$ güç yoğunluğu elde edilmiştir. Grafen ile modifiye edilmiş NiTi elektrot ile üretilen güç miktarının literatürle kıyaslandığında, son yıllarda yenilikçi elektrot malzemeleri ile yapılan birçok çalışmadan daha yüksek olduğu tespit edilmiştir. Literatürdeki mevcut çalışmalarda Yamashita ve Yokoyama (2018) molibden bir elektrot kullanılarak $1296 \mathrm{~mW} / \mathrm{m}^{2}$ güç üretimi elde etmişlerdir. Zeng ve diğ., (2018) makro gözenekli karbonize polidopamin modifiye pamuklu tekstil ile $931 \pm 61 \mathrm{~mW} / \mathrm{m}^{2}$ güç yoğunluğu elde ettiklerini rapor etmişlerdir. Diğer bir çalışmada ise Rikame ve diğ., (2018) indirgenmiş grafen oksit/polipirol kullanarak modifiye ettikleri grafit elektrotu kullanarak $835.21 \pm 1.40 \mathrm{~mW} / \mathrm{m}^{3}$ güç yoğunluğuna ulaşmışlardır. Grafen kaplı NiTi elektrot kullanılarak elde edilen güç miktarı $\left(2043 \mathrm{~mW} / \mathrm{m}^{2}\right)$ güncel literatürdeki değerler ile kıyaslandığında oldukça yüksek olduğu görülmektedir. 

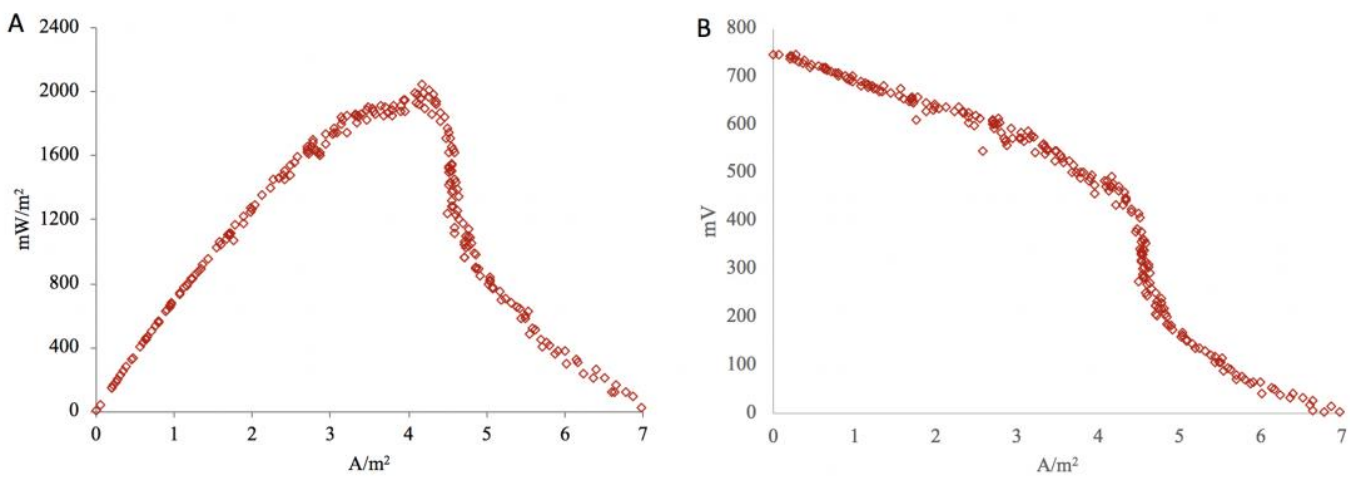

Şekil 2. MYH’de üretilen güç yoğunluğu (A) ve polarizasyon eğrisi (B)

MYH performansını gösteren diğer bir önemli parametre ise iç direnç değeridir. MYH sisteminin iç direnci güç üretimini etkileyen en önemli faktördür. Bu amaçla kullanılan MYH reaktöründe nyquist analizi yapılmış ve elde edilen sonuçlara model uygulanarak iç direnç değeri detaylı bir şekilde tespit edilmiştir. Nyquist sonucu ve sonuçlara uygulanan model Şekil 3'de görülmektedir. Buna göre NiTi elektrota ait anot yük transfer direnci, katot elektrotuna ait yük transfer direnci ve sistemin solüsyon direnci sirası ile 371.7, 2.9 ve $63.1 \Omega$ dur. MYH reaktöründe oluşan toplam iç direnç değeri $437.7 \Omega$ dur. Taskan ve Hasar (2015) tarafindan yapılan bir çalışmada kalay kaplı bakır mesh elektrotun kullanıldığı çift bölmeli bir MYH'de 477 S'luk bir iç direnç elde edilmiştir. Karbon kumaş elektrotun kullanıldığı bir çalışmada toplam iç direnç değeri $366 \Omega$ olarak rapor edilmiştir [14]. Diğer bir çalışmada, biyolojik olarak indirgenmiş grafen oksit film elektrot ile modifiye edilmemiş elektrotların kullanıldığı MYH reaktörleri için iç direnç değerleri sırası ile $299.11 \Omega$ ve $375.21 \Omega$ olarak belirlenmiştir [15]. Yousefi ve diğ., (2016) tarafından yapılan bir diğer çalışmada grafit granül yataklı anotun kullanıldığı üç farklı MYH'de elde edilen iç direnç değerlerinin 614.71-1711.59 $\Omega$ aralığında olduğu rapor edilmiştir. Grafen ile kaplanmış NiTi elektrot için elde edilen iç direnç değeri literatür değerleri ile kıyaslandığında nispeten düşük bir iç direnç değerinin meydana geldiğini ve bu değerin literatür değerleri ile kıyaslanabileceği görülmektedir. NiTi alaşımının yüksek elektriksel iletkenliği ve grafen kullanılarak yapılan yüzey modifikasyonu, anot yüzeyine olan elektron transferini kolaylaştırarak MYH'de meydana gelen iç direnci düşürmüştür.

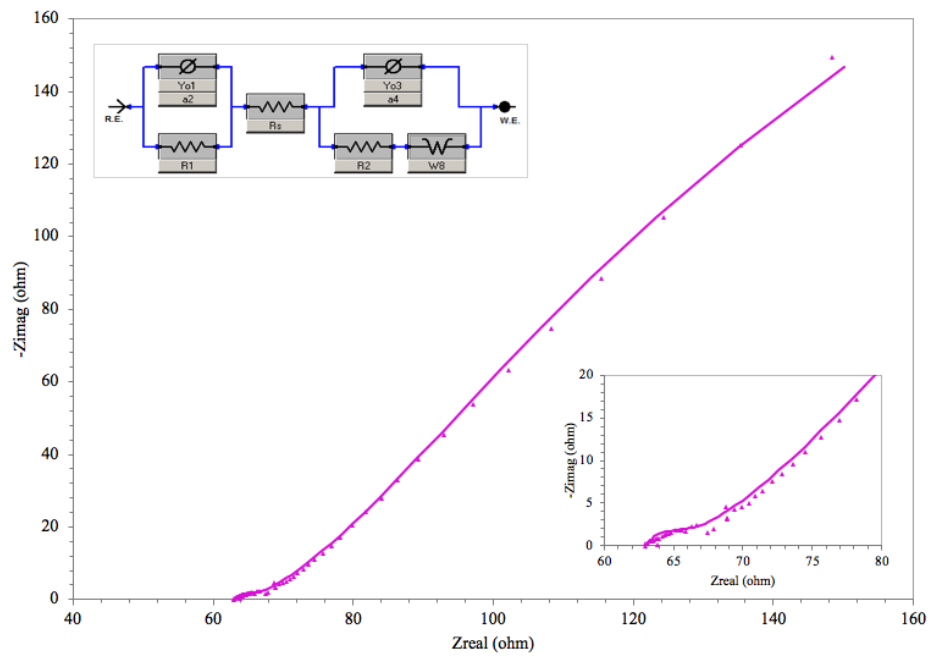

Şekil 3. Anot elektrotuna ait Nyquist diyagramı

\subsection{Mikrobiyal kommunite analizi}

MYH reaktörünün işletme süresi sonunda anot yüzeyinden alınan biyofilm numunesinde aktif bakterilere ait genomik DNA izole edilmiştir. Daha sonra izole edilen DNA numunesine PCR ve DGGE işlemleri uygulanarak 
bakteri türlerinin tanımlanması sağlanmıştır. DGGE analiz sonucuna göre elde edilen jel görüntüsünde anot yüzeyindeki biyofilm yapısında mikrobiyal çeşitliliğin mevcut olduğu ve Comamonas sp. (KX225269), Uncultured Geobacter sp. (JF817816), Shewanella oneidensis (AB447987), Uncultured Pseudomonas sp. (GQ329590), Pseudomonas aeruginosa (JQ912281) gibi türlerin varlı̆̆ı belirlenmiştir (Şekil 4). Shewanella türleri c-tipi sitokromlara sahip olup anot elektrotuna kolay bir şekilde tutunabilir ve ürettikleri elektronları sahip oldukları nanowire'lar sayesinde anota rahat bir şekilde transfer edebilirler [17]. Pseudomonas türleri ise fenazin tabanlı kimyasalları üretme yeteneğine sahip olup bu kimyasallar MYH'de medyatör görevi görmektedir [18]. Diğer taraftan Geobacter türlerinin elektron transferinden sorumlu c-tipi sitokrom genine sahip olduğu literatür çalışmalarında rapor edilmiștir [19]. Bu türler yüksek elektrik üretme yeteneğine sahip olan elektrojen türler olarak bilinmektedir. Commault ve diğ., (2013) grafit elektrotun kullanıldığı bir MYH'de Geobacter türünün baskın olduğu bir biyofilm ile $270 \mathrm{~mW} / \mathrm{m}^{2}$ güç üretimi sağlamıştır. Narayanasamy ve Jayaprakash (2018) tarafindan yapılan bir çalıșmada grafit/polyester kompozit elektrot kullanılan bir MYH'de Pseudomonas aeruginosa biyofilmi kullanılarak azo boyası degredasyonu ile $1575 \pm 223.26 \mu \mathrm{W} / \mathrm{m}^{2}$ güç üretilebildiği rapor edilmiştir.

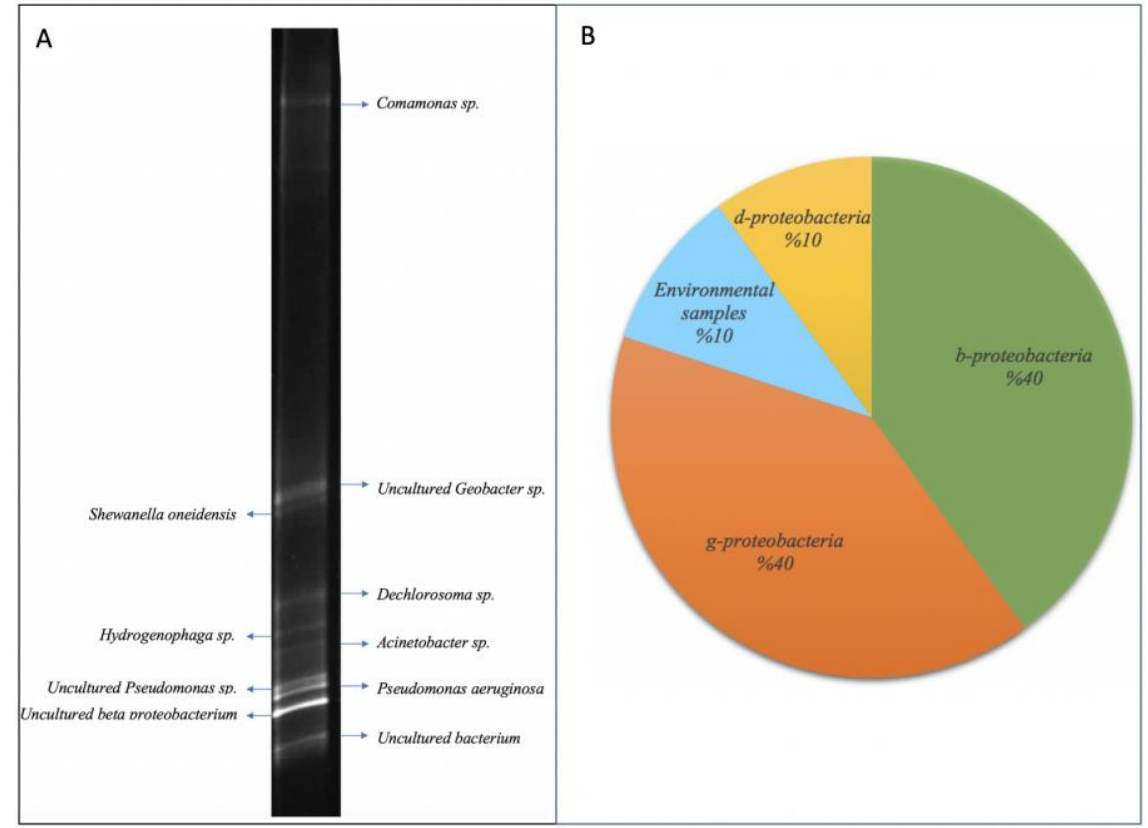

Şekil 4. A: Anot elektrotu yüzeyinden alınan biyofilm numunesine ait DGGE jel görüntüsü, B: Baskın tür sinifları

Moleküler çalışma sonucunda grafen kaplı NiTi elektrot yüzeyinde tespit edilen mikroorganizma türlerinin b-proteobacteria (\%40), d-proteobacteria (\%10), g-proteobacteria (\%40) ve Environmental bacteria (\%10) gruplarına ait olduğu belirlenmiştir (Şekil 4B). Bu bakteri gruplarının daha önceki çalışmalarda anot biyofilminde farklı oranlarda mevcut olduğu rapor edilmiştir [21,22] . Deltaproteobacteria grubuna ait bakterilerin anot yüzeyinde kolonize oldukları ve ürettikleri elektronları anot yüzeyine kolay bir şekilde aktarabildikleri bilinmektedir [23-26]. Moleküler analiz sonuçları, grafen kaplı NiTi elektrotun elektroaktif türlerin varlığını desteklediği ve biyofilm yapısında tür çeşitliliğinin mevcut olduğunu göstermiştir.

\subsection{SEM sonuçları}

Sekil 5'de NiTi alaşımının yüzeyinden alınan SEM görüntüleri verilmiștir. Mevcut NiTi alaşımı düz bir yüzey yapısına sahiptir. Düz yapı, bakteriyel tutunma için uygun bir ortam oluşturmamaktadır. 

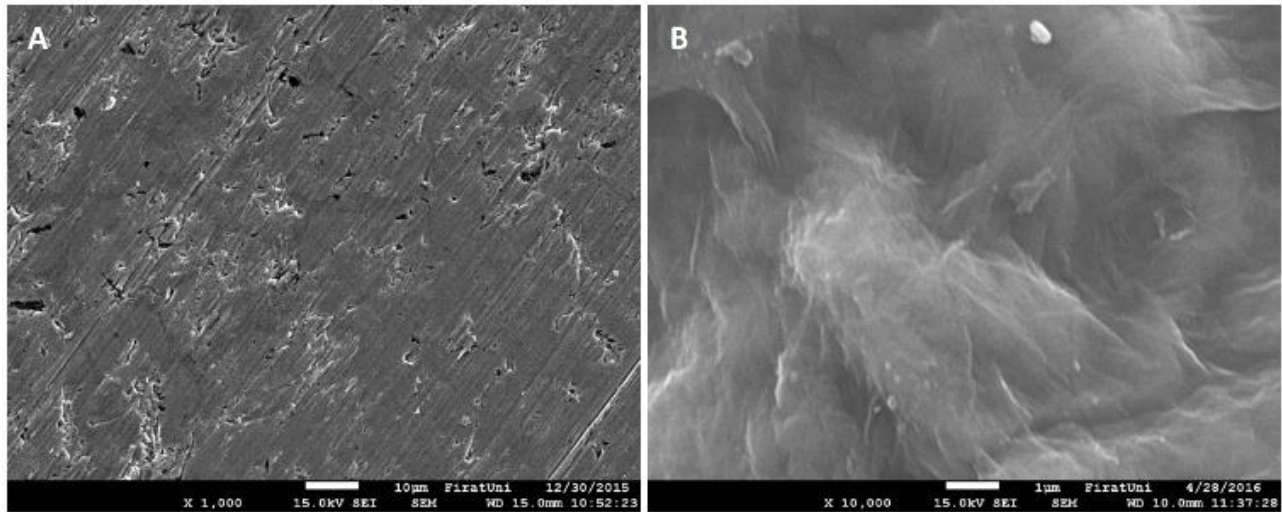

Şekil 5. Anot elektrotunun işletmeden önce yüzeyine ait SEM görüntüleri; (A) grafen kaplamasız, (B) grafen kapl1

Literatürde yapılan çalışmalarda pürüzlü yüzey morfolojisinin bakteriyel tutunmayı arttırdığı rapor edilmiştir [27-29]. Cheng ve diğ., (2018) tarafindan yapılan çalışmada, grafit firça elektrot grafen nanokompozit kullanılarak kaplanmıştır. Uygulanan yüzey modifikasyonu ile üretilen güç miktarının 3,2 kat arttığını belirtmişlerdir. Bu çalışmada düz bir yüzey yapısına sahip olan NiTi elektrotun yüzey özelliklerinin iyileştirilmesi için grafen ile modifikasyon (kaplama) işlemi yapılmıştır. Grafen kullanılarak yapılan kaplama işlemi mikroorganizmalar için tutunma alanını arttırmasının yanında yüzey pürüzlülüğü ve biyolojik uyumluluğu arttırmıştır. Bu yapı mikroorganizmalar için uygun bir tutunma alanı ve iyi bir elektron transfer yüzeyi sağlamaktadır (Şekil 5B). MYH reaktörünün işletme süresinin sonunda elektrot yüzeyinden alınan SEM görüntüleri Şekil 6'da görülmektedir. Anot yüzeyinden farklı noktalardan alınan SEM görüntülerinde elektrot yüzeyindeki biyofilm yapısı ve bakteriyel morfoloji görülmektedir. SEM görüntülerinde bioyofilm yapısında genellikle yuvarlak şekilli mikroorganizmaların varlığı tespit edilirken nadir olarak çubuksu mikroorganizmaların da varlığı gözlenmiştir. Biyofilm yapısındaki bakterilerin boyutlarının yaklaşık olarak $1 \mu \mathrm{m}$ olduğu görülmektedir. SEM görüntüleri yeni geliştirilen elektrot malzemesinin bakterilerin tutunması için uygun bir ortam oluşturduğunu göstermektedir.
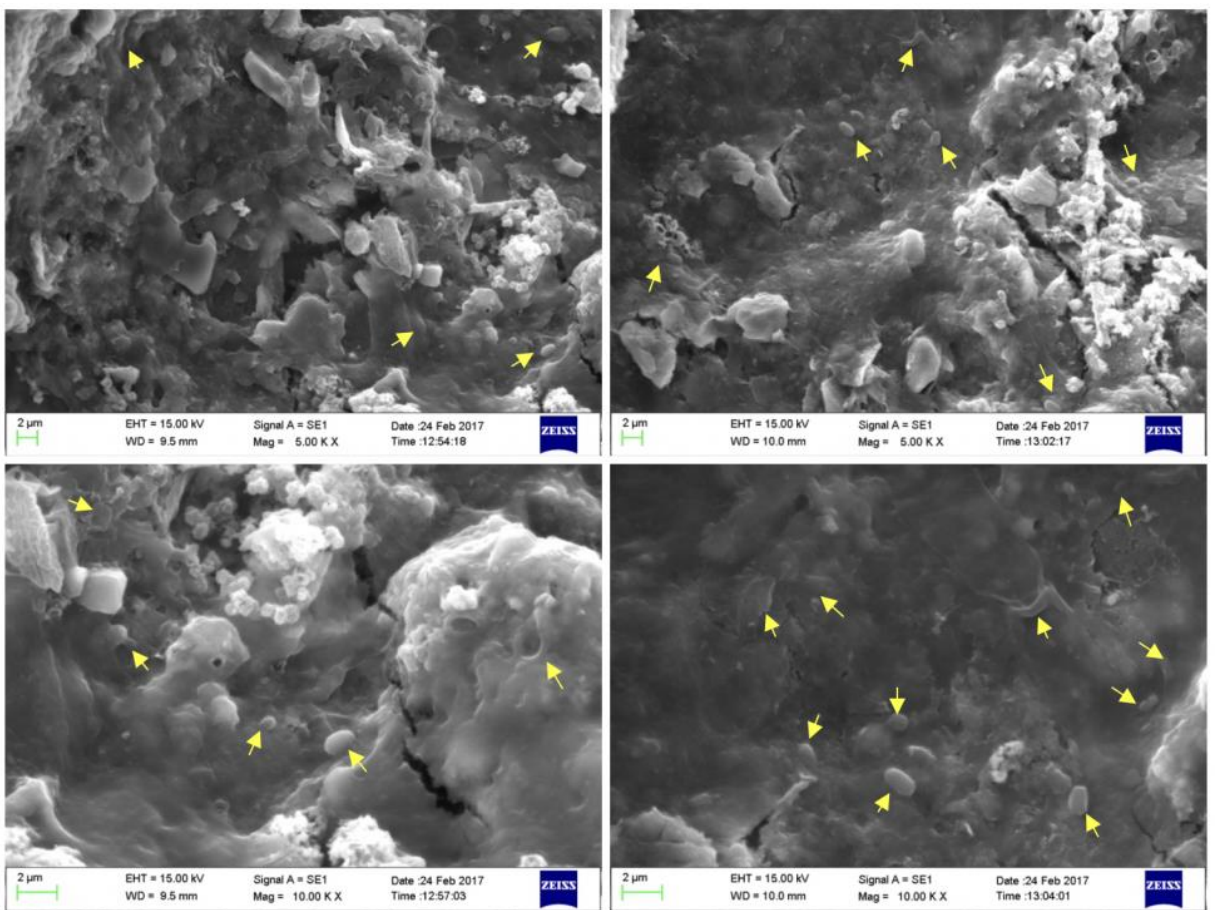

Şekil 6. İşletmeden sonra anot elektrot yüzeyinden alınan SEM görüntüsü 


\section{Sonuçlar}

Bu çalışmada grafen kaplı NiTi alaşımı MYH'de elektrot malzemesi olarak ilk defa kullanılmıştır. MYH reaktörünün ürettiği maksimum güç miktarı $2043 \mathrm{~mW} / \mathrm{m}^{2}$ olarak elde edilmiştir. Anot biyofilmine uygulanan moleküler analizler ve SEM sonuçları elektrot yüzeyinde iyi bir biyofilm tabakasının mevcut olduğunu ve elektroaktif türlerin varlığını göstermiştir. Bu sonuçlar yeni geliştirilen elektrot malzemesinin mikroorganizmalar ile biyouyumluluğunun yüksek olduğunu ifade etmektedir. Sonuç olarak yeni geliştirilen elektrot malzemesinin elektrik üretim performansı literatür çalışmalarına kıyasla nispeten yüksek olup ileriki çalışmalara 1 şık tutabilecektir.

\section{Teșekkürr}

Bu çalışma TÜBİTAK-CNRST ikili iş birliği programı kapsamında 114Y699 nolu proje ile desteklenmiştir. TÜBİTAK'a katkılarından dolayı teşekkür ederiz.

\section{Kaynaklar}

[1] Logan BE. (2008). Microbial fuel cells. ed. John Wiley \& Sons.

[2] Taskan E, Hasar H. Comprehensive Comparison of a New Tin-Coated Copper Mesh and a Graphite Plate Electrode as an Anode Material in Microbial Fuel Cell. Appl. Biochem. Biotechnol 2015; 175(4): 2300-2308.

[3] Li S, Cheng C, Thomas A. Carbon-Based Microbial-Fuel-Cell Electrodes: From Conductive Supports to Active Catalysts. Adv. Mater 2017; 29(8): 1602547.

[4] Toker SM, Canadinc D, Maier HJ, Birer O. Evaluation of passive oxide layer formation-biocompatibility relationship in NiTi shape memory alloys: Geometry and body location dependency. Mater. Sci. Eng., C 2014; 36(118-129.

[5] Akdoğan A, Nurveren K. Akıllı Malzemeler ve Uygulamaları. Machinery MakinaTek 2002; 57 s 35):

[6] Hou J, Liu Z, Li Y, Yang S, Zhou Y. A comparative study of graphene-coated stainless steel fiber felt and carbon cloth as anodes in MFCs. Bioprocess Biosyst Eng 2015; 38(5): 881-888.

[7] Hsu W-H, Tsai H-Y, Huang Y-C. Characteristics of Carbon Nanotubes/Graphene Coatings on Stainless Steel Meshes Used as Electrodes for Air-Cathode Microbial Fuel Cells. J Nanomater 2017; 2017 (

[8] Xiao L, Damien J, Luo J, Jang HD, Huang J, He Z. Crumpled graphene particles for microbial fuel cell electrodes. J. Power Sources 2012; 208(187-192.

[9] Zhang Y, Mo G, Li X, Zhang W, Zhang J, Ye J, Huang X, Yu C. A graphene modified anode to improve the performance of microbial fuel cells. J. Power Sources 2011; 196(13): 5402-5407.

[10] Zheng S, Yang F, Chen S, Liu L, Xiong Q, Yu T, Zhao F, Schröder U, Hou H. Binder-free carbon black/stainless steel mesh composite electrode for high-performance anode in microbial fuel cells. J. Power Sources 2015; 284(252-257.

[11] Yamashita T, Yokoyama H. Molybdenum anode: a novel electrode for enhanced power generation in microbial fuel cells, identified via extensive screening of metal electrodes. Biotechnol Biofuels 2018; 11(1): 39.

[12] Zeng L, Zhao S, He M. Macroscale porous carbonized polydopamine-modified cotton textile for application as electrode in microbial fuel cells. J. Power Sources 2018; 376(33-40.

[13] Rikame SS, Mungray AA, Mungray AK. Modification of anode electrode in microbial fuel cell for electrochemical recovery of energy and copper metal. Electrochim. Acta 2018; 275(8-17.

[14] Cheng P, Shan R, Yuan H-R, Deng L-f, Chen Y. Enhanced Rhodococcus pyridinivorans HR-1 anode performance by adding trehalose lipid in microbial fuel cell. Bioresour Technol 2018; 267(774-777.

[15] Wang K, Cheng Y, Chen Y, Jin X, Chen Z. Green reduced graphene oxide electrodes by eucalyptus leaves extract to enhance the power generation of microbial fuel cells (MFC). Huanjing Kexue Xuebao/Acta Scientiae Circumstantiae 2017; 37(8): 2944-2950.

[16] Yousefi V, Mohebbi-Kalhori D, Samimi A, Salari M. Effect of separator electrode assembly (SEA) design and mode of operation on the performance of continuous tubular microbial fuel cells (MFCs). Int. J. Hydrogen Energy 2016; 41(1): 597-606.

[17] El-Naggar MY, Wanger G, Leung KM, Yuzvinsky TD, Southam G, Yang J, Lau WM, Nealson KH, Gorby YA. Electrical transport along bacterial nanowires from <em>Shewanella oneidensis</em> MR-1. Proc Natl Acad Sci 2010; 107(42): 18127-18131.

[18] Pham TH, Boon N, De Maeyer K, Höfte M, Rabaey K, Verstraete W. Use of Pseudomonas species producing phenazinebased metabolites in the anodes of microbial fuel cells to improve electricity generation. Appl Microbiol Biotechnol 2008; 80(6): 985-993.

[19] Commault AS, Lear G, Packer MA, Weld RJ. Influence of anode potentials on selection of Geobacter strains in microbial electrolysis cells. Bioresour Technol 2013; 139(226-234.

[20] Narayanasamy S, Jayaprakash J. Improved performance of Pseudomonas aeruginosa catalyzed MFCs with graphite/polyester composite electrodes doped with metal ions for azo dye degradation. Chem. Eng. J 2018; 343(258-269. 
[21] Wang J, Song X, Wang Y, Bai J, Bai H, Yan D, Cao Y, Li Y, Yu Z, Dong G. Bioelectricity generation, contaminant removal and bacterial community distribution as affected by substrate material size and aquatic macrophyte in constructed wetland-microbial fuel cell. Bioresour Technol 2017; 245(372-378.

[22] Sawasdee V, Pisutpaisal N. Microbial Community from Tannery Wastewater in Microbial Fuel Cell. Chemical Engineering Transactions 2018; 64(397-402.

[23] Logan BE. Exoelectrogenic bacteria that power microbial fuel cells. Nat Rev Microbiol 2009; 7(5): 375.

[24] Bond DR, Holmes DE, Tender LM, Lovley DR. Electrode-reducing microorganisms that harvest energy from marine sediments. Science 2002; 295(5554): 483-485.

[25] Lee J, Phung NT, Chang IS, Kim BH, Sung HC. Use of acetate for enrichment of electrochemically active microorganisms and their 16S rDNA analyses. FEMS Microbiol Lett 2003; 223(2): 185-191.

[26] Holmes DE, Bond DR, O'Neil RA, Reimers CE, Tender LR, Lovley DR. Microbial Communities Associated with Electrodes Harvesting Electricity from a Variety of Aquatic Sediments. Microb Ecol 2004; 48(2): 178-190.

[27] Thung W-E, Ong S-A, Ho L-N, Wong Y-S, Ridwan F, Oon Y-L, Oon Y-S, Lehl HK. Bioelectricity Generation in BatchFed Up-Flow Membrane-Less Microbial Fuel Cell: Effect of Surface Morphology of Carbon Materials as Aqeuous Biocathodes. Water, Air, Soil Pollut 2016; 227(8): 254.

[28] Tao Y, Liu Q, Chen J, Wang B, Wang Y, Liu K, Li M, Jiang H, Lu Z, Wang D. Hierarchically Three-Dimensional Nanofiber Based Textile with High Conductivity and Biocompatibility As a Microbial Fuel Cell Anode. Environ. Sci. Technol 2016; 50(14): 7889-7895.

[29] You J, Santoro C, Greenman J, Melhuish C, Cristiani P, Li B, Ieropoulos I. Micro-porous layer (MPL)-based anode for microbial fuel cells. Int. J. Hydrogen Energy 2014; 39(36): 21811-21818.

[30] Cheng Y, Mallavarapu M, Naidu R, Chen Z. In situ fabrication of green reduced graphene-based biocompatible anode for efficient energy recycle. Chemosphere 2018; 193(618-624. 